\title{
Caries prevalence, clinical consequences and self-reported pain experienced by children living in the West Bank
}

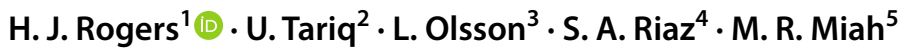

Received: 4 May 2018 / Accepted: 13 December 2018 / Published online: 25 March 2019

(c) The Author(s) 2019

\begin{abstract}
Aim To investigate both caries prevalence and clinical consequences experienced by deprived children in the West Bank, using a child-centred approach.

Materials and methods Children were invited by their social workers to attend free dental screening sessions held across clinics in the north of the West Bank. Data were collected using the dmft/DMFT and pufa/PUFA indices. Dental pain was reported by children using the Wong-Baker FACES® pain scale. Data were analysed using SPSS Version 22.0.

Results Data were collected for 177 children aged 4 to 18 years. Caries prevalence was $95.5 \%$ with only eight children presenting clinically caries-free. The sample had a dmft of 3.88, and DMFT of 3.44. The Care Index was calculated at 0.1 (mft/ $\mathrm{dmft}$ ). Clinical consequences of caries were identified in $64 \%$ of the sample, with a mean pufa score of 2.12 , and a PUFA score of 0.55 . Dental pain was experienced by $45 \%$ of children.

Conclusion Deprived children living in the West Bank experience high levels of untreated dental caries, with significant clinical consequences and self-reported pain.
\end{abstract}

Keywords Caries $\cdot$ Deprivation $\cdot$ Child-centred

\section{Introduction}

The situation in the West Bank can only be described as uncertain. There is ongoing conflict, high military presence and a tense atmosphere. The possibility of a peaceful twostate solution is looking unlikely, which has had adverse economic effects. Growth rates have been slow since the 2014 conflict, and unemployment figures are high, estimated at $18 \%$ in the West Bank (World Bank 2017). Donor related income has increased although this is unsustainable in the long run due to continued border restrictions and political stagnation (World Bank 2017).

\section{H. J. Rogers}

Hrogers1@sheffield.ac.uk

1 Academic Unit of Oral Health, Dentistry and Society, School of Clinical Dentistry, University of Sheffield, Sheffield, UK

2 Lauriston Dental Care, Edinburgh, UK

3 Departments of Oral Medicine and Oral Surgery, Glasgow Dental Hospital, Glasgow, UK

4 The Avenue Dental Surgery, Greater Manchester, UK

5 DHS Dental, Oldham, UK
Dental Aid Network (DAN) is a registered charity founded by a group of dentists in Glasgow, United Kingdom. The charity aims to provide humanitarian aid to those less fortunate in order to prevent and relieve pain and suffering from dental disease. DAN volunteers work closely with the Palestinian Children's Relief Fund (PCRF) in several areas of Nablus; a city in the north of the West Bank approximately 30 miles north of Jerusalem with an estimated population of 125,000 .

The DAN team have undertaken several aid missions to Nablus over a number of years, working together with local dentists to help secure the oral health of Palestinian children currently affected by the difficult political situation (Dental Aid Network 2017). The 2016/17 DAN mission allowed the team to improve the oral health of disadvantaged children, whilst providing an opportunity to further explore the impact of oral disease on children living within this conflict zone. This study aimed to investigate both caries prevalence and the clinical consequences of caries experienced by the children in the West Bank, using a child-centred approach. 


\section{Materials and methods}

This cross-sectional study was undertaken alongside the DAN mission to the West Bank in December 2016. Local approval for this study was gained through the Palestine Children's Relief Fund, in accordance with the Declaration of Helsinki guidance.

A convenience sample was formed of children and adolescents who attended a free dental screening session run by the DAN team at three clinics in the area. Local social workers invited children under their care to attend, many of whom lived in deprived circumstances, had lost one or both parents or had additional needs, such as learning difficulties or hearing impairments. Consent for data collection was provided by the primary caregiver, and verbal assent was sought from children and adolescents themselves. Standardised data collection forms were designed to systematically record dmft/DMFT, pufa/PUFA and pain scores as described below.

The $\mathrm{dmft} / \mathrm{DMFT}$ index has been widely used for over half a century as a means of collecting easily comparable data on caries prevalence and treatment provision from different populations (Klein et al. 1938; Monse et al. 2010). Nonetheless, this index fails to consider the clinical consequences of untreated caries-an important indicator of dental neglect addressed by the pufa/PUFA index. The pufa index was proposed in 2010 by Monse and co-workers to gain data regarding the severity of oral conditions related to untreated caries (Monse et al. 2010). Since conception, it has been used successfully with children in a variety of settings including those with limited access to dental care (Baginska et al. 2013; Grund et al. 2015; Ramazani et al. 2017). The 'p' corresponds to pulpal involvement, 'u' for ulceration arising as a result of a carious tooth, 'f' for a fistula and ' $a$ ' for a dental abscess.

The Arabic translation of the Wong-Baker FACES $₫$ pain scale was used to gain children's report of dental pain. This measure was developed in 1988 and has been validated for use with children as young as 3 years and older (Wong-Baker FACES® Foundation 2015). Laminated copies of the Wong-Baker FACES $₫$ pain scale were available in each clinic.

Data were collected by 11 dental professionals from different occupational backgrounds and with varying levels of experience. The team took part in a 3-h training and calibration exercise prior to data collection, involving familiarisation with the indices through a series of example cases.

Dental screenings were held across three clinics-one in Nablus centre and one in each of the neighbouring towns of Salfeet and Qalqilya. Examinations were undertaken according to the World Health Organisation (WHO) diagnostic criteria, using a dental chair, light and mirror. Teeth were dried using cotton wool only. Whilst each team member had some knowledge of the Arabic language, interpreters were provided where required. Following data collection, the children were offered subsequent appointments to have the recommended treatment completed.

Collected data were analysed for descriptive statistics using SPSS Version 22.0. Correlations between dmft/DMFT, pufa/ PUFA and pain scores were analysed using Pearson's correlation coefficient.

\section{Results}

Data were collected for 177 children aged 4-18 years $($ mean $=11$ years; median $=11$ years $)$ with a male to female ratio of $3: 2$.

The overall caries prevalence was $95.5 \%$ with only 8 children presenting clinically caries-free. Mean caries experience (Table 1) in the primary dentition was $3.88 \mathrm{dmft}$, with 3.44 for the decayed component. The Care Index for the primary dentition can be calculated at $0.1(\mathrm{mft} / \mathrm{dmft})$ with only eight children having received restorations. Mean caries experience in the permanent dentition was 3.44 DMFT, with 2.98 for the decayed component. In the permanent dentition, 18 children had received restorations and 15 had undergone extractions, placing the Care Index at 0.1 .

The overall presence of clinical consequences of caries, identified using the pufa/PUFA index was $64 \%$. The mean pufa index for the primary dentition was 2.12 , and the PUFA index for the permanent dentition was 0.55. The 'Untreated Caries, PUFA Ratio' was calculated at $(2.67 / 6.42 \times 100) 42 \%$. This indicates that $42 \%$ of the decayed primary and permanent teeth had developed an odontogenic infection (Monse et al. 2009). Significant correlations $(\rho<0.005)$ were identified between high dmft/DMFT and pufa/PUFA scores $(\rho=0.000$ for primary and permanent teeth). As the data were non-parametric, the Mann-Whitney $U$ test was undertaken to identify any differences between males and females for dmft/DMFT and pufa/ PUFA scores. As seen in Table 1, no significant differences were identified.

Dental pain (Fig. 1) was experienced by $45 \%$ of the children, with $17 \%(n=29)$ experiencing lower levels of pain (scores $1-5)$ and $27 \%(n=47)$ reporting higher levels of pain (scores 6-10). Pain scores were missing for three participants and hence were excluded from this part of the analysis. No significant correlations were found between change in pain score and pufa/PUFA or dmft/DMFT scores. 
Table 1 Prevalence (dmft/ DMFT) and clinical consequences (pufa/PUFA) of dental caries experienced by this sample

\begin{tabular}{|c|c|c|c|c|c|c|c|c|c|c|}
\hline \multirow[t]{4}{*}{ Number (\%) } & \multicolumn{4}{|l|}{ Gender } & \multirow[t]{4}{*}{. $\mathrm{Sig}$} & \multicolumn{5}{|c|}{ Overall (\%) } \\
\hline & \multirow{2}{*}{\multicolumn{2}{|c|}{$\frac{\text { Male (\%) }}{106(60)}$}} & \multirow{2}{*}{\multicolumn{2}{|c|}{$\frac{\text { Female }(\%)}{71(40)}$}} & & & & & & \\
\hline & & & & & & \multicolumn{5}{|l|}{$177(100)$} \\
\hline & Median & IQR & Median & IQR & & Minimum & Maximum & Median & IQR & Mean \\
\hline $\mathrm{dt}$ & 3 & 6 & 1 & 5 & 0.149 & 0 & 19 & 2 & 6 & 3.44 \\
\hline $\mathrm{mt}$ & 0 & 0 & 0 & 0 & 0.197 & 0 & 8 & 0 & 0 & 0.38 \\
\hline $\mathrm{ft}$ & 0 & 0 & 0 & 0 & 0.101 & 0 & 2 & 0 & 0 & 0.06 \\
\hline Total dmft & 4 & 7 & 2 & 6 & 0.137 & 0 & 19 & 3 & 7 & 3.88 \\
\hline DT & 2 & 4 & 3 & 4 & 0.978 & 0 & 16 & 3 & 4 & 2.98 \\
\hline MT & 0 & 0 & 0 & 0 & 0.998 & 0 & 5 & 0 & 0 & 0.15 \\
\hline FT & 0 & 0 & 0 & 0 & 0.757 & 0 & 8 & 0 & 0 & 0.27 \\
\hline Total DMFT & 3 & 4 & 3 & 3 & 0.784 & 0 & 16 & 3 & 3 & 3.44 \\
\hline $\mathrm{p}$ & 1 & 3 & 0 & 3 & 0.302 & 0 & 14 & 0 & 3 & 1.92 \\
\hline $\mathrm{u}$ & 0 & 0 & 0 & 0 & 0.413 & 0 & 2 & 0 & 0 & 0.01 \\
\hline$f$ & 0 & 0 & 0 & 0 & 0.471 & 0 & 3 & 0 & 0 & 0.09 \\
\hline $\mathrm{a}$ & 0 & 0 & 0 & 0 & 0.75 & 0 & 5 & 0 & 0 & 0.1 \\
\hline Total pufa & 1 & 4 & 0 & 3 & 0.207 & 0 & 17 & 0 & 4 & 2.02 \\
\hline $\mathrm{P}$ & 0 & 0 & 0 & 1 & 0.384 & 0 & 6 & 0 & 0 & 0.48 \\
\hline $\mathrm{U}$ & 0 & 0 & 0 & 0 & 1 & 0 & 0 & 0 & 0 & 0 \\
\hline $\mathrm{F}$ & 0 & 0 & 0 & 0 & 0.534 & 0 & 1 & 0 & 0 & 0.02 \\
\hline A & 0 & 0 & 0 & 0 & 0.187 & 0 & 1 & 0 & 0 & 0.05 \\
\hline Total PUFA & 0 & 0 & 0 & 1 & 0.416 & 0 & 6 & 0 & 1 & 0.55 \\
\hline
\end{tabular}

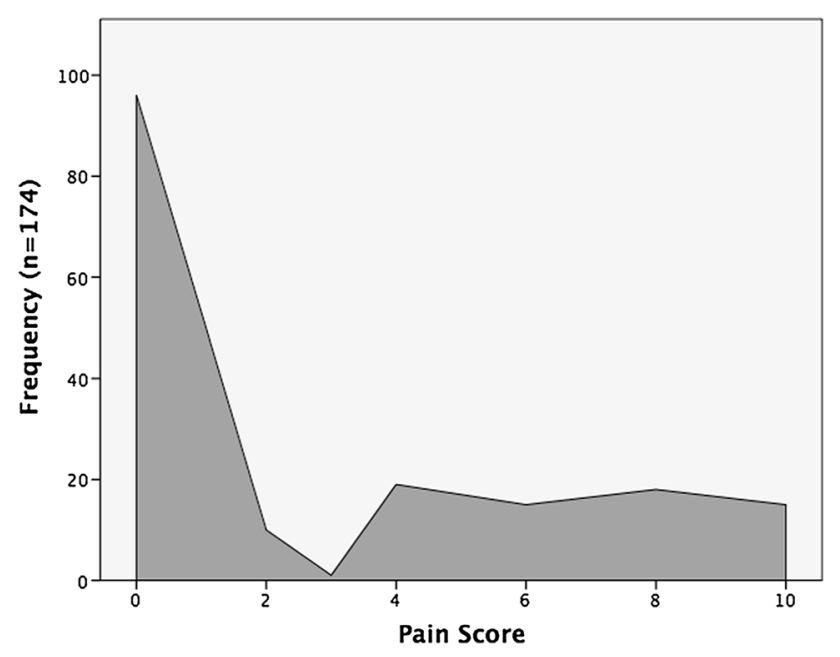

Fig. 1 Graph displaying frequency and severity of pain experienced by the sample population

\section{Discussion}

Using three validated indices this study reports data on caries prevalence, impacts and consequences, representative of deprived and orphaned children living in the West Bank.

Children and young people participating in the current study had an average dmft/DMFT of 3.88/3.44, which is comparable to other studies investigating caries prevalence in children and adolescents in the West Bank (Livny et al. 2007; Mahfouz and Abu Esaid 2014). Nonetheless, these figures are significantly higher than those seen in the neighboring country of Jordan, which has a reported mean $\mathrm{dmft} / \mathrm{DMFT}$ of 2.8/0.7 (Rajab et al. 2002). Moreover, a recent systematic review reported an average $\mathrm{dmft}$ of 3.3 and DMFT of 1.1 for children living in the Arab-league countries (Khan 2014). This indicates that children living in the West Bank have a higher caries prevalence than those living in other parts of this transcontinental region.

The association between dental caries and socioeconomic deprivation is widely acknowledged (Watt et al. 1999; Mathur et al. 2014; Schwendicke et al. 2014) and will have contributed greatly to these findings. A high percentage of the population in the West Bank live in poverty which is partly due to the occupation of the territory and economic sanctions facing the country (United Nations Development Programme 2015). The poverty line by national standards for Palestine, as set by Palestinian Central Bureau of Statistics (PCBS) in 2011, is 2293 NIS (\$637) per month for a family of two adults and three children, based on the average consumption of essential food, clothing, housing, housekeeping, personal supplies, health care, education, and transportation. The most recent survey estimated that nearly $20 \%$ of West Bank's population lived in poverty and $7.8 \%$ were considered to be in 'deep poverty' which calculates as 
a family income of less than $\$ 509$ a month (Palestinian Central Bureau of Statistics 2007). The impact of this situation on children's general health is significant, with a reported $33.5 \%$ of children suffering from anaemia in the West Bank and 2.9\% from acute malnutrition (Quota and Odeh 2005).

The Palestinian Ministry of Health operates 41 dental clinics which provide subsidised treatment for over 4 million children and adults across the West Bank and Gaza (AlAttrash 2014). Nonetheless, individuals must have governmental health insurance to be able to access these services, and certain interventions, such as endodontic treatment, are not routinely provided. A large proportion of dental care in Palestine is provided via private dental clinics or NonGovernmental Organisations.

Further to the financial barriers to families accessing dental care, a physical restriction is often present. Many residents in the West Bank and Gaza are required to obtain specific travel permission to pass through occupied territory, or move between different areas of the West Bank. Not only can this prevent families trying to access dental care, but it can also limit the provision of dental care, and importation of dental equipment (Kateeb 2007). A low care index was present in both the primary and permanent dentitions of our sample; 1.55 and 7.85 respectively, indicating that few participants had received prior dental treatment. This is in stark contrast to the United Kingdom, where $90 \%$ of children visited a dentist in 2013 accessing free-of-charge dental care via the National Health Service (NHS) (ONS 2015).

Dental pain was reported by almost half of the sample, presenting with clinical consequences of untreated dental caries, primarily pulpal involvement and fistulae. The prevalence of pufa/PUFA recorded in this sample was $64 \%$. Whilst there are few studies available that can afford a direct comparison due to the specific sample characteristics of the present study, it can be noted that this is a relatively high prevalence in comparison to other populations. For example, the prevalence of pufa/PUFA was reported at $55.7 \%$ in a study of Filipino schoolchildren by Benzian and coworkers (2011). Pulpal involvement was identified in $47 \%$ of primary teeth and $25 \%$ of permanent teeth in our sample, consistent with findings from research by Ramazani and coworkers (2017) who reported pulpal involvement to be the most commonly reported clinical consequence. Whilst the present study did not explore the wider impact of clinical consequences of caries, the aforementioned study by Benzian and coworkers (2011) identified an increased risk of having a 'below normal' BMI in children with caries into the pulp when compared to children without odontogenic infections, emphasising the important role of oral health as a deterministic factor for general health.

Almost half of the children in this sample reported some form of dental pain $(n=80,45 \%)$. This is slightly higher than previous research by Slade (2001), which found toothache to be reported by up to $30 \%$ of young children from deprived areas. Further impacts relating to pain have also been widely reported such as time off school, difficulty sleeping and speaking and interference with daily activities (Ratnayake 2005; Pau et al. 2007; Krisdapong et al. 2009b). As anticipated, pain experience in this sample was positively correlated with an increase in dmft/DMFT and pufa/PUFA.

\section{Strengths, limitations and generalisability}

This aid mission facilitated an opportunity to explore the prevalence, clinical consequences and impacts of caries in a vulnerable population in an unstable part of the world. To the authors knowledge, this is the first dental study in the West Bank to use a child-reported outcome measure.

Self-report of children's pain is considered to be the gold standard and preferred over observational reports, given that pain is a subjective experience (Franck et al. 2000; Wong et al. 2015). Furthermore, by involving children in this way, this study has acknowledged current recommendations to actively involve children in research (Marshman and Hall 2008; UN Convention 2009). It is anticipated that this will encourage further involvement of children in research as active participants in the Middle East.

As data for this study was collected during a humanitarian aid mission, the volunteers ranged in experience, from recently-graduated dentists, to those with specialist training in oral surgery and paediatric dentistry. One dentist had received formal training in DMFT assessment and provided a calibration session for the rest of the dentists prior to commencing data collection. Nonetheless, the inter-examiner variance may have reduced the reliability of the results recorded. One suggestion to improve the accuracy of diagnosis would be the use of bitewing radiographs. However dental radiography is not commonly employed for WHO studies on dental caries, and was not available for use during this aid mission.

Local staff helped with translation during assessments, with only three of the assessing dentists able to speak the native language. Whilst this language barrier may have presented some difficulties when taking a dental history or undertaking treatment, it is unlikely to have interfered with data collection. All data collection was undertaken through clinical assessment with the exception of the pain scores. For this component, written instructions in Arabic were provided for children, advising them to simply point to the number that best represented their current pain experience.

The sample size of this study was relatively small for an epidemiological study, and it should be noted that the findings may not relate to all children in the West Bank, as our subjects were mainly those of the lowest level of deprivation, such as orphans and those with additional needs. Nonetheless, whilst the findings from this study hold limited 
generalisability, they contribute to a limited evidence base in a conflict zone.

\section{Future considerations}

The Palestinian Ministry of Health initiated a school-based screening programme in 1997, aiming to address the difficulties in accessing dental care. This programme provided oral health education, and referred students with caries to Ministry of Health operated clinics for treatment. Whilst a slight reduction in overall $\mathrm{dmft} / \mathrm{DMFT}$ was noted during the years 2002 to 2004, it remains clear that a predominantly preventative programme is key (Kateeb 2007). The success of the NHS-funded Scottish programme 'Childsmile', introduced in 2008, provides supervised toothbrushing, the distribution of toothpaste and toothbrushes to families with young children, and twice yearly high fluoride varnish application in nurseries, schools and in the primary dental care setting (Macpherson et al. 2012). This cost-effective strategy has led to an increase in the number of children with no caries experience, from $53 \%$ of 11 -year-old children in 2005 to $75 \%$ in 2015 (SDECC 2015). Whilst a preventative programme such as this would benefit the children living in the West Bank, it must be acknowledged that this would be difficult to implement in light of the current political situation.

The DAN team intends to revisit the West Bank on an annual basis, and hopes to establish a permanent dental clinic for children in this area. Through collection of data over a number of years the team can evaluate the effectiveness of their preventive strategies in the region, using the data collected in the present study as a baseline.

\section{Conclusions}

This study provides baseline epidemiological data to show the high levels of untreated dental caries experienced by children and young people living in deprivation in the West Bank. Furthermore, this study highlights the significant clinical consequences of untreated dental disease, including selfreported pain. It is anticipated that this research can support future studies investigating the effectiveness of preventative interventions in this part of the world.

Acknowledgements Dental Aid Network would like to acknowledge the support from PCRF and all the sponsors who made this mission possible. If you are interested in volunteering on a future mission please email info@dentalaidnetwork.org or follow us on Twitter: @ AidDental.

Funding No research funding was obtained for this project. The aid mission was self-funded by each Dental Aid Network volunteer, though costs were subsidised by the Palestine Childrens Relief Fund (PCRF) - a nonprofit humanitarian organization based in the Middle
East. Materials and equipment were also kindly donated for this mission by a number of sponsors.

\section{Compliance with ethical standards}

Conflict of interest The authors report no conflicts of interest.

Ethical approval All procedures performed in studies involving human participants were in accordance with the ethical standards of the institutional and/or national research committee and with the 1964 Helsinki declaration and its later amendments or comparable ethical standards.

Informed consent Informed consent was obtained from all individual participants included in the study.

OpenAccess This article is distributed under the terms of the Creative Commons Attribution 4.0 International License (http://creativeco mmons.org/licenses/by/4.0/), which permits unrestricted use, distribution, and reproduction in any medium, provided you give appropriate credit to the original author(s) and the source, provide a link to the Creative Commons license, and indicate if changes were made.

\section{References}

Al-Attrash F. A bright smile for palestinians. 2014. http://archive.thisw eekinpalestine.com/details.php?id=1587\&ed=111\&edid=111. Accessed 22 Apr 2017.

Bagińska J, Rodakowska E, Wilczyńska-Borawska M, et al. Index of clinical consequences of untreated dental caries (pufa) in primary dentition of children from North-East Poland. Adv Med Sci. 2013;58(2):442-7.

Benzian H, Monse B, Heinrich-Weltzien R, et al. Untreated severe dental decay: a neglected determinant of low body mass index in 12-year-old Filipino children. BMC Public Health. 2011;11(1):558.

Dental Aid Network. About Us. 2017. http://www.dentalaidnetwor k.org. Accessed 22 Apr 2017.

Franck L, Greenberg C, Stevens B. Pain assessment in infants and children. Pediatr Clin North Am. 2000;47:1-32.

Grund K, Goddon I, Schüler IM, et al. Clinical consequences of untreated dental caries in German 5- and 8-year-olds. BMC Oral Health. 2015. https://doi.org/10.1186/s12903-015-0121-8.

Kateeb E. Evaluation of the ministry of health school oral health programme in the west bank region of palestine. East Mediterr Health J. 2007;13(3):595-607.

Khan S. Dental caries in Arab League countries: a systematic review and meta-analysis. Int Dent J. 2014;64(4):173-80. https://doi. org/10.1111/idj.12092.

Klein H, Palmer C. Studies on dental caries: VI. Caries experience and variation in the time of eruption of the permanent teeth. Child Dev. 1938. https://doi.org/10.2307/1125573.

Livny A, Assali R, Sgan-Cohen H. Early childhood caries among a bedouin community residing in the eastern outskirts of Jerusalem. BMC Public Health. 2007. https://doi. org/10.1186/1471-2458-7-167.

Macpherson LMD, Anopa Y, Conway DI, et al. National supervised toothbrushing program and dental decay in Scotland. J Dent Res. 2012;92(2):109-13.

Marshman Z, Hall MJ. Oral health research with children. Int J Pediatr Dent. 2008;18(4):235-42. https://doi.org/10.1111/j.1365263X.2008.00922.x. 
Mahfouz M, Abu Esaid A. Dental caries prevalence among 12-15 year old palestinian children. Int Sch Res Not. 2014. https://doi. org/10.1155/2014/785404.

Mathur M, Tsakos G, Parmar P, et al. Socioeconomic inequalities and determinants of oral hygiene status among Urban Indian adolescents. Commun Dent Oral Epidemiol. 2016;44(3):248-54. https ://doi.org/10.1111/cdoe.12212.

Monse B, Heinrich-Weltzien R, Benzian H, et al. PUFA-An index of clinical consequences of untreated dental caries. Commun Dent Oral Epidemiol. 2010;38(1):77-82. https://doi.org/10.111 1/j.1600-0528.2009.00514.x.

Office for National Statistics. Social Survey Division. (2015) Children's dental health survey, 2013. [data collection]. UK data service. SN: 7774. https://doi.org/10.5255/UKDA-SN-7774-1. Accessed Feb 2017.

Palestinian Central Bureau of Statistics.2007. http://pcbs.gov.ps/site/ lang_en/507/default.aspx. Accessed 22nd Apr 2017.

Pau A, Baxevanos KG, Croucher R. Family structure is associated with oral pain in 12-year-old Greek schoolchildren. Int J Paediatr Dent. 2007;17(5):345-51.

Qouta S, Odeh J. The impact of conflict on children: the palestinian experience. 2005. http://www.healingdivides.org/wp/the-impac $\mathrm{t}$-of-conflict-on-children-the-palestinian-experience. Accessed 22nd Apr 2017.

Rajab LD, Hamdan MA. Early childhood caries and risk factors in Jordan. Community Dent Health. 2002;19(4):224-9.

Ratnayake N, Ekanayake L. Prevalence and impact of oral pain in 8-year-old children in Sri Lanka. Int J Paediatric Dent. 2005; 15:105-12.

Ramazani N, Rezaei S. Evaluation of the prevalence of clinical consequences of untreated dental caries using PUFA/pufa index in a group of Iranian children. Iran J Pediatrics. 2017;27(1):1-6. https ://doi.org/10.5812/ijp.5016.

Schwendicke F, Dörfer C, Schlattmann P, et al. Socioeconomic inequality and caries. J Dent Res. 2014;94(1):10-8. https://doi. org/10.1177/0022034514557546.
Slade GD. Epidemiology of dental pain and dental caries among children and adolescents. Community Dent Health. 2001;18(4):219-27.

The Scottish Dental Epidemiology Co-ordinating Committee. National dental inspection programme (NDIP) 2015 [Internet]. 2015. http:// ndip.scottishdental.org/wp-content/uploads/2015/10/ndip_scotl and2015-P7.pdf.

United Nations. General Comment No. 12: the right of the child to be heard (No. $\mathrm{UN}=\mathrm{CRC}=\mathrm{C}=\mathrm{GC}=12$ ). Geneva: United Nations; 2009.

United Nations Development Programme. The 2014 Palestine Human Development Report [Internet]. 2015. https://reliefweb.int/sites /reliefweb.int/files/resources/UNDP-papp-research-PHDR2015. pdf. Accessed 22 Apr 2017.

Watt R, Sheiham A. Health policy: Inequalities in oral health: a review of the evidence and recommendations for action. Br Dent $\mathrm{J}$. 1999;187(1):6-12.

Wong M, Copp PE, Haas DA. Postoperative pain in children after dentistry under general anesthesia. Anesth Prog. 2015;62(4):140-52. https://doi.org/10.2344/14-27.1.

Wong-Baker FACES, Foundation. (2016). Wong-Baker FACES® Pain Rating Scale. Retrieved with permission from http://www.WongB akerFACES.org. Originally published in Whaley \& Wong's Nursing Care of Infants and Children (C) Elsevier Inc. Accessed 22 Apr 2017.

World Bank. (2017). West Bank and Gaza. http://www.worldbank.org/ en/country/westbankandgaza/overview\#3. Accessed 22 Apr 2017.

Publisher's Note Springer Nature remains neutral with regard to jurisdictional claims in published maps and institutional affiliations. 